\title{
Rendas do petróleo e eficiência tributária dos municípios brasileiros ${ }^{\dagger}$
}

\author{
Carlos Roberto Alves de Queiroz* \\ Fernando Antonio Slaibe Postali*
}

\begin{abstract}
RESUMO - Este artigo apresenta os resultados de uma investigação do impacto das rendas do petróleo (royalties e participações especiais) sobre o esforço tributário das localidades atualmente contempladas. Utiliza-se a metodologia de fronteiras estocásticas, considerando o IPTU per capita como variável definidora de produção de impostos. Investiga-se, também, como as rendas do petróleo explicam as ineficiências arrecadatórias dos municípios. Os resultados sugerem haver indícios de redução de esforço fiscal dos municípios mais beneficiados com tais recursos.
\end{abstract}

Palavras-chave: Rendas do petróleo. Eficiência tributária. Impostos municipais.

\section{INTRODUÇÃO}

As descobertas de grandes reservas de petróleo e gás natural na camada pré-sal da plataforma continental brasileira trouxeram, para a pauta política do país, o debate sobre a adequação do atual marco regulatório da atividade petrolífera, que antes estava restrito à pauta acadêmica e ao mercado. Uma das facetas deste debate trata da discussão sobre a divisão das rendas governamentais do petróleo entre os entes federados (União, Estados e Municípios). Da forma como foram estabelecidas no marco regulatório vigente, as rendas governamentais do petróleo ${ }^{1}$ podem ser consideradas transferências intergovernamentais sem contrapartida e sem vinculação, segundo as definições de Shah (1994). Tanto a Teoria do Federalismo Fiscal como diversos trabalhos empíricos nesta área mostram que estas espécies de transferências tendem a diminuir o esforço fiscal dos entes receptores.

Dada a importância da discussão para as contas públicas nacionais e a atualidade do problema exposto, convém verificar se os atuais beneficiários de rendas do petróleo têm esforço fiscal reduzido. Isto posto, são objetivos deste breve artigo apresentar um método econométrico capaz de estimar os impactos da percepção de rendas do petróleo no esforço fiscal dos municípios contemplados e verificar se este efeito, esperado pela teoria, tem ocorrido no Brasil sob a égide do atual marco regulatório da indústria petrolífera. Espera-se que ao cabo este trabalho possa contribuir com a discussão da redistribuição das rendas governamentais do

\footnotetext{
† Uma versão resumida deste artigo foi publicada no Boletim de Informações FIPE (BIF), de agosto de 2010.

*Graduado em economia pela FEA/USP. Endereço Eletrônico: craqueiroz@gmail.com.

** Doutor em economia pela Universidade de São Paulo. É professor doutor da Universidade de São Paulo. Endereço Eletrônico: postali@usp.br.

1 Doravante, o termo petróleo se referirá também a gás natural, quando não houver confusão de sentido.
} 
petróleo, que está em debate no Congresso Nacional.

Nos anos 1990, inspirado nas ideias de revisão do papel do Estado na economia, o governo FHC implantou importantes modificações na estrutura institucional da indústria petrolífera no Brasil, inaugurando um novo marco regulatório para o setor, que vige até hoje. De acordo com este marco regulatório, implantado pela Emenda Constitucional No 9/95 e pela Lei No 9478/97 (também conhecida como Lei do Petróleo), o Estado é proprietário dos recursos minerais (inclusive o petróleo e o gás natural), mas transfere as atividades de exploração e de produção a empresas, por meio de contratos de concessão. O Estado, então, é remunerado por compensações financeiras (participações ou rendas governamentais) pagas pelos concessionários.

Neste modelo, definiram-se quatro tipos de participações ou rendas governamentais: royalties, participações especiais, bônus de assinatura e pagamento pela ocupação ou retenção de área. Os royalties e as participações especiais são divididos entre a União e os Estados e Municípios produtores ou afetados (direta ou indiretamente) pela atividade petrolífera ${ }^{2}$. As duas últimas rendas ficam à disposição do governo federal.

O valor das receitas de royalties percebido pelos Estados e Municípios que atendem aos critérios de produção e afetação é proporcional à produção dos poços alocados nos mesmos. Para Serra (2003), tais critérios apresentam severas distorções. Um exemplo aparece quando a lavra ocorre na plataforma continental (offshore ou em alto mar). Nestes casos, os Estados e os Municípios são qualificados como produtores de acordo com a projeção de suas circunscrições geográficas em direção ao mar, e as receitas de royalties a que têm direito de receber são proporcionais às produções dos poços dentro destas projeções. Assim, dependendo da forma de suas costas, os "produtores" incluem mais ou menos poços dentro de sua área, recebendo, assim, mais ou menos royalties. Para o citado autor, este critério contempla a "sorte geográfica", em detrimento de razões socioeconômicas.

As indenizações para as localidades produtoras de petróleo estão previstas desde a regulamentação varguista de 1953, que também criou a Petrobrás. No entanto, somente a partir da Lei do Petróleo é que os recursos destinados aos Estados e Municípios produtores e afetados aumentaram substancialmente, em virtude das mudanças trazidas pelo novo marco regulatório, dentre as quais destacamos:

- $\quad$ elevação da alíquota dos royalties - um imposto ad valorem sobre a produção bruta de óleo - de 5\% para 10\%, sendo que os Estados e Municípios produtores e afetados foram

2 Da parcela dos royalties destinada à União e aos Estados produtores, uma pequena parte deve ser distribuída a todos os Municípios brasileiros. 
favorecidos na distribuição deste acréscimo de $5 \%$;

- criação das participações especiais, que são uma espécie de bônus à União e aos

Estados e Municípios produtores nos casos de grande volume de produção e de grande rentabilidade;

- $\quad$ instituição de um novo preço de referência para o cálculo do valor dos royalties (e das participações especiais), com base em uma cesta de tipos de óleos comercializados no mercado internacional ${ }^{3}$;

- $\quad$ desvinculação nas aplicações das rendas governamentais, visto que a Lei anterior $(7527 / 86)$ permitia o uso destes recursos somente para investimentos em energia, meio ambiente, saneamento e rodovias ${ }^{4}$;

Como fruto destas transformações na legislação, houve um incremento substancial nas receitas de recursos do petróleo (royalties + participações especiais), assim como uma maior margem de manobra para sua aplicação.

\section{GRÁFICO 1 - REPASSES DE ROYALTIES POR ESFERA DE GOVERNO, 1994-2008}

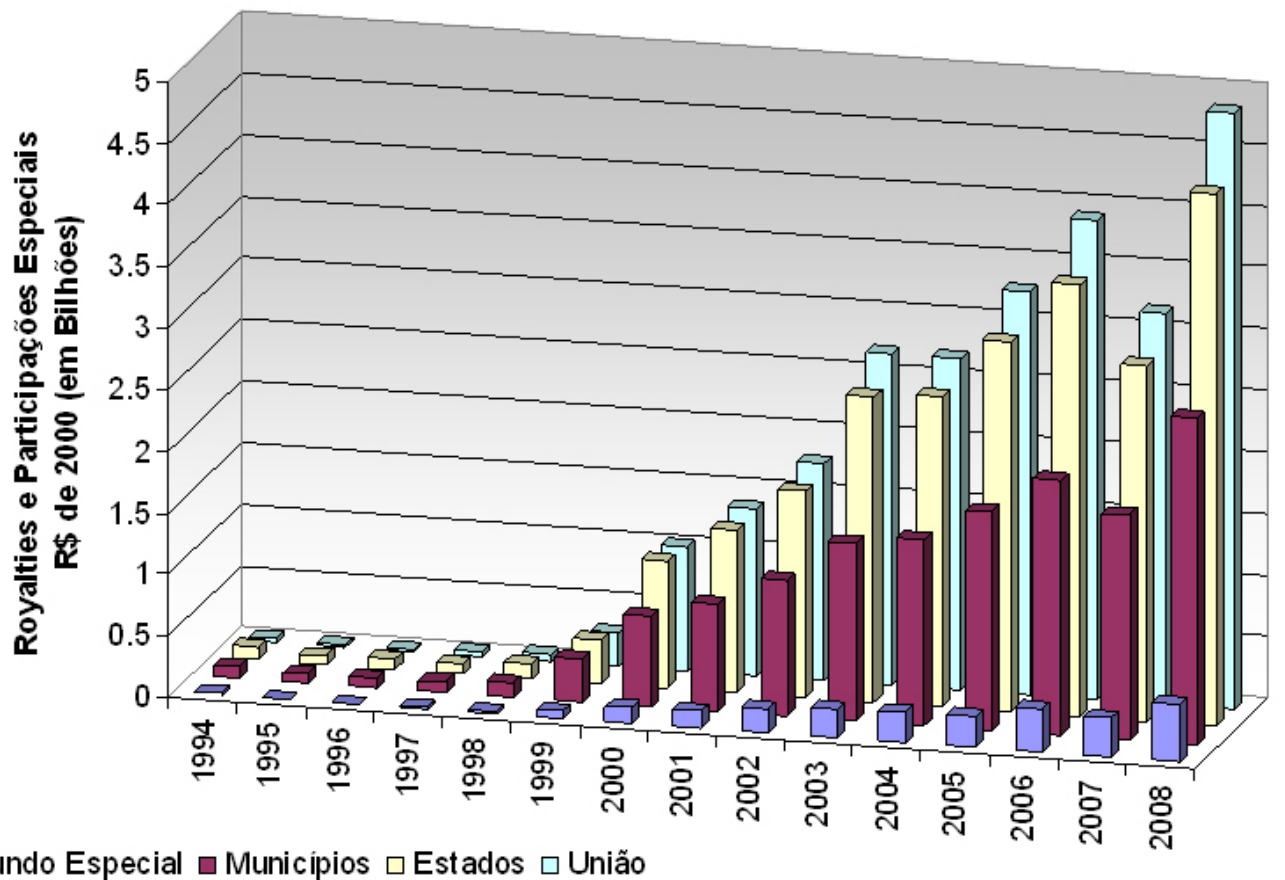

$\square$ Fundo Especial $\square$ Municipios $\square$ Estados $\square$ União

FONTE: Elaboração própria a partir de dados da Agência Nacional do Petróleo - ANP.

3 Esta mudança permitiu que as rendas petrolíferas se tornassem bem mais sensíveis às oscilações da cotação do petróleo. Pela regra anterior, os royalties eram calculados com base no preço fixado na refinaria o que tornava a arrecadação bastante inelástica diante de variações no preço internacional.

4 Um parecer do Tribunal de Contas do Rio de Janeiro, em decisão que só vale naquele Estado, entendeu que os royalties do petróleo não podem ser utilizados para gastos em folha de pagamento e serviços da dívida. 
De fato, como resultado da nova configuração legal, a arrecadação de royaltie ${ }^{5}$ cresceu $^{-}$ de forma significativa após 1999, quando começaram a vigorar todas as mudanças implementadas, conforme se observa no gráfico acima, onde Fundo Especial representa os recursos do Fundo Especial do Petróleo, que é distribuído para todos os Municípios brasileiros, e as legendas para Estados e Municípios representam os entes produtores ou afetados pela produção.

As descobertas do pré-sal, que ampliaram ainda mais as potencialidades do Brasil na indústria do petróleo, incentivaram o governo Lula a propor ao Congresso Nacional, na forma de Projetos de Lei, várias alterações no marco regulatório vigente. No entanto, nenhuma alteração na forma de distribuição das rendas governamentais geradas pela atividade petrolífera foi proposta pelo Poder Executivo. Coube à Câmara dos Deputados, através da chamada Emenda Ibsen $^{6}$, a proposição de alterações nas regras de distribuição das rendas governamentais. Em linhas gerais, todos os Estados e Municípios do país passariam a se beneficiar diretamente das rendas do petróleo, tanto das atuais concessões como das áreas do pré-sal, cujo regime de produção deve ser o de partilha. Como consequência, os atuais grandes beneficiários, pelos critérios da Lei do Petróleo (9478/97), incorreriam em severas perdas. A proposta contendo a Emenda Ibsen foi aprovada na Câmara dos Deputados e atualmente tramita no Senado Federal. Caso ela seja aprovada no Senado sem mais alterações, se tornará Lei após sanção presidencial.

\section{RENDAS DO PETRÓLEO E FINANÇAS MUNICIPAIS}

O pagamento ou a apropriação de rendas do petróleo por entes governamentais justifica-se por dois princípios básicos da Ciência Econômica: escassez e externalidades. Com relação à escassez, deve-se ter em mente que o petróleo é um recurso não-renovável, ou seja, que não possui um ciclo natural de renovação em um horizonte de tempo finito. Assim sendo, ele representa um estoque de capital à disposição da sociedade. À medida que a produção petrolífera ocorre, esse estoque se deteriora fisicamente (depleta-se). Desta forma, a captura de rendas do petróleo a partir da cobrança de royalties representa uma compensação, ao proprietário de um ativo, pela depreciação do seu estoque de capital, conforme a produção se desenrola. A apropriação deste tipo de compensação também é justificada como forma de garantia do bem estar intergeracional, visto que os recursos depletados não estarão à disposição das gerações futuras. Serra (2005) e Bregman (2007) defendem ainda a utilização de rendas governamentais para a captura das rendas extraordinárias ${ }^{7}$ muito comuns na indústria petrolífera e que, na inércia do

5 Doravante, o termo royalties também englobará as participações especiais, quando se referir às indenizações devidas ou pagas aos entes beneficiários.

6 Apresentada pelo Deputado Ibsen Pinheiro (PMDB/RS).

7 Entendidas como aquelas que superam a remuneração dos demais ativos. 
poder concedente, serão apropriadas pelas empresas concessionárias.

As razões explicitadas no parágrafo anterior justificam a apropriação de rendas governamentais pela União, pois é dela, por direito, a propriedade dos recursos minerais. No entanto, a atividade petrolífera impacta as localidades onde ocorre a sua produção gerando toda a sorte de externalidades. Neste sentido, justifica-se a apropriação de rendas pelas esferas governamentais locais ou subnacionais, que devem utilizar estas compensações na mitigação dos efeitos negativos, como os danos ambientais. Outros pontos que merecem destaque e que justificam a percepção de rendas governamentais são a necessidade de os governos locais oferecerem melhores serviços públicos para atendimento da demanda extraordinária gerada pela atividade produtiva e o posterior esvaziamento da região produtora quando o ciclo produtivo se completar ${ }^{8}$.

Uma questão pouco investigada e que merece preocupação refere-se ao impacto de tais receitas sobre o incentivo dos Municípios em diversificar sua base de arrecadação tributária. Em outras palavras, os Municípios beneficiários de elevados montantes de rendas do petróleo podem cair na tentação de reduzir o seu esforço fiscal.

A fim de se compreender como estas variáveis podem estar relacionadas, preliminarmente, deve-se entender a natureza econômica dos royalties nos orçamentos municipais. Basicamente, os orçamentos dos Municípios são compostos, principalmente, de tributos arrecadados diretamente por eles (e pagos pelos seus munícipes) e de transferências efetuadas pelas outras esferas de governo, financiadas com tributos pagos por contribuintes de todos os Municípios. A evidência empírica sugere que os Municípios preferem substituir a sua arrecadação própria pelas transferências provenientes de outras esferas. Em geral, quanto mais o orçamento de uma localidade depende de transferências da União e dos Estados, maior sua ineficiência na coleta de impostos locais. Evidências nesta direção são reportadas por Reis e Blanco (1996), Cossio (1998), Ribeiro e Shikida (2000), Aragon e Gayoso (2005), dentre outros.

Segundo Shah (1994), este efeito ocorre quando as ditas transferências são classificadas como sem contrapartida, no sentido de que o ente receptor não colabora com o seu custeio, e sem vinculação, de modo que os gastos destas transferências não estão vinculados a nenhum fim específico. Nestes casos, o administrador municipal tem um incentivo a compensar o aumento da receita advindo da transferência com uma redução da arrecadação de impostos.

8 Os efeitos das rendas do petróleo sobre os municípios têm sido objeto de diversos estudos, como os de Costa Nova (2005), Fernandes (2007), Givisiez e Oliveira (2008), Bregman (2007), Postali (2009), Postali e Nishijima (2008). No geral, as evidências são inconclusivas, tendendo para a má utilização dos recursos, de modo que apenas alguns indicadores econômicos e sociais localizados melhoraram em alguns grandes beneficiários de royalties, ao passo que muitos outros não melhoraram ou evoluíram de maneira diferenciada em relação à média nacional, havendo, ainda, piora em alguns casos. 


\section{METODOLOGIA E RESULTADOS}

Conforme observado na seção anterior, a percepção de rendas do petróleo deve reduzir o esforço fiscal dos Municípios beneficiados. O esforço fiscal de um ente público pode ser definido como o grau de aproveitamento da sua capacidade fiscal (arrecadação potencial) e pode ser estimado através da relação entre a arrecadação observada e a potencial estimada. A necessidade de estimação da arrecadação potencial justifica a utilização de um método econométrico alternativo ao de mínimos quadrados ordinários, visto que este não é capaz de mostrar qual a arrecadação máxima que se pode obter em determinadas condições, mas apenas aquilo que, em média, é arrecadado nestes casos (Reis e Blanco, 1996). Neste sentido, a utilização do método de fronteiras estocásticas de produção se justifica, pois a sua capacidade de estimação de um produto máximo (ou potencial) a partir de uma série de insumos pode ser aproveitada para o nosso problema, se considerarmos que a arrecadação potencial municipal é o nosso produto e que as características econômicas do Município são os nossos insumos. A analogia faz sentido pois a base tributária de uma localidade, que define a sua capacidade de arrecadação, está relacionada às suas macro-variáveis como população, PIB, etc.

Considerando também que o que se quer é relacionar uma suposta ineficiência (arrecadatória) com uma causa provável (recebimento de royalties), o método de fronteiras estocásticas também deve estimar uma relação correta e consistente entre estas variáveis. A metodologia de fronteiras estocásticas de produção com efeitos de ineficiência, desenvolvida em Battese e Coelli (1995), contempla estas necessidades. Resumidamente, a metodologia compreende a estimação uma fronteira eficiente de produção ${ }^{9}$, na qual a arrecadação de impostos é modelada como uma função de produção, explicada por variáveis indicativas da capacidade fiscal dos municípios, como o PIB per capita e sua população, e, simultaneamente, a ineficiência técnica é modelada como função da dependência das rendas do petróleo, medida pela razão entre a receita de royalties e a receita corrente dos municípios.

Queiroz e Postali (2010) estimaram os impactos do recebimento de royalties na arrecadação total municipal e na arrecadação de IPTU (Imposto Predial e Territorial Urbano) e ISS (Imposto Sobre Serviços), que são os principais impostos arrecadados nesta esfera de governo. No geral, obtiveram evidências de que os royalties do petróleo explicam as ineficiências na coleta dos impostos municipais, o que pode ser entendido como uma redução do esforço fiscal ocasionado pela percepção desses recursos. A título de ilustração, neste trabalho transcrevemos daquele os resultados obtidos para o IPTU, que se mostrou o imposto mais sensível à percepção de rendas do petróleo no seguinte modelo:

9 Ver detalhes metodológicos em Aigner, Lovell e Schmidt (1976); Battese (1992); Battese e Coelli (1995). 


$$
\begin{aligned}
& \ln \left(\text { iptupc }_{i t}\right)=\underset{(0.07024)^{*}}{-0.7162}+\underset{(0.01066)^{*}}{1.8893} \operatorname{lpibpc_{it})}+\underset{(0.00685)^{*}}{0.1031} \ln \left(\text { pop }_{i t}\right)
\end{aligned}
$$

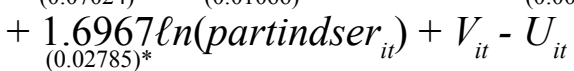

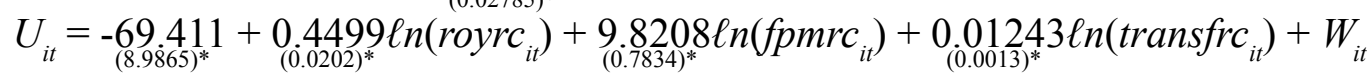

Onde iptupc $c_{i t}$ é a arrecadação de IPTU per capita do município $i$ no ano $t$, pibpc $c_{i t}$ é o respectivo PIB per capita, pop $p_{i t}$ é a população e partindser ${ }_{i t}$ é a soma das participações dos PIB's industrial e de serviços no PIB total do Município. Esta variável tem o objetivo de controlar para a base arrecadatória do IPTU, tendo em vista que sua arrecadação está fortemente associada ao grau de urbanização do Município. $V_{i t}$ é um distúrbio aleatório que pode assumir valores maiores, menores ou iguais a zero e é independente e identicamente distribuído (i.i.d.), com $V_{\text {it }}$ $\sim N\left(0, \sigma^{2}\right) . U_{i t}$ tem distribuição truncada não-negativa $\left(U_{i t} \geq 0\right) \operatorname{com} U_{i t} \sim N\left(0, \sigma^{2}\right)$ e é a parte do erro que representa a ineficiência técnica. Royrc $c_{i t}$ é a relação entre as receitas de royalties do município $i$ no ano te a sua receita corrente; $\not p m r c_{i t}$ é a razão entre a receita do Fundo de Participação do Município e sua receita corrente e transfr $c_{i t}$ é a relação entre as transferências estaduais para o Município e sua receita corrente. Estas variáveis procuram captar o grau de dependência do Município em relação às rendas do petróleo e às transferências de outros níveis da federação. $W_{i t} \sim N\left(0, \sigma^{2}\right)$ é um distúrbio aleatório.

Os dados de arrecadação do IPTU foram extraídos do FINBRA, da Secretaria do Tesouro Nacional (STN). A receita municipal de royalties foi obtida junto à ANP - Agência Nacional do Petróleo. As informações sobre a população municipal foram extraídas das projeções anuais do IBGE e os dados referentes ao PIB foram obtidos no IPEADATA. A composição destas informações resultou em um banco de dados composto por cerca de 4200 municípios observados de 1999 a 2005. Destes, aproximadamente 500 são beneficiários de receitas de royalties e participações especiais, segundo os critérios da Lei 9478/97.

Todos os coeficientes estimados mostraram-se de acordo com o esperado e representam as elasticidades entre as variáveis, visto que foram utilizados seus logaritmos naturais. Analogamente, todos os resultados são significativos a 1\%, sendo que os respectivos desviospadrão encontram-se entre parênteses, abaixo das estimativas dos parâmetros.

Na primeira equação, que estima a capacidade de arrecadação do IPTU, observamos que todas as variáveis contribuem para o aumento da capacidade arrecadatória, ou seja, Municípios com maiores PIB per capita (mais ricos), mais populosos e com grande participação da indústria e dos serviços na produção (mais urbanizados), são mais capazes de arrecadar IPTU. Destaque-se a alta elasticidade para PIB per capita (1.88) e para o grau de urbanização (1.69).

A segunda equação procura explicar a ineficiência técnica na arrecadação do IPTU, 
que é a diferença entre a variável $i p t u p c_{i t}^{*}$ (estimada) e a observada. Notamos que a dependência de todas as transferências estudadas (royalties, FPM e estaduais) tem relação positiva e significativa com a ineficiência na arrecadação do IPTU. Deste modo, quanto maiores forem os repasses de royalties e as transferências estaduais e do FPM, mais ineficiente o Município será na arrecadação do IPTU. Note-se que, de acordo com a elasticidade estimada, aumentos de 1\% nas receitas de royalties, induzem a aumentos de ineficiência na arrecadação de IPTU da ordem de quase 0,45\%. Em Queiroz e Postali (2010), mostra-se ainda que as estatísticas de teste confirmam o bom ajustamento do modelo utilizado.

\section{CONSIDERAÇÕES FINAIS}

Neste breve artigo tratamos da relação entre royalties do petróleo e esforço fiscal no âmbito dos municípios atualmente beneficiados com rendas governamentais de petróleo. Verificamos que a utilização de uma metodologia econométrica não usual foi necessária para que pudéssemos captar a relação pretendida e estimar os efeitos entre as variáveis de análise. Em seguida, constatamos que o benefício dos royalties, em que pese ser plenamente justificável como vimos na seção 3, pode induzir ineficiências no sistema fiscal dos Municípios beneficiados, de maneira que o esforço na arrecadação do IPTU é afetado quando o Município percebe royalties do petróleo. Frise-se ainda que quanto maior a participação dos royalties na receita corrente dos Municípios, menor é o esforço despendido na arrecadação do IPTU per capita, ou menor é o interesse da municipalidade em aproveitar a sua base tributária.

Os resultados obtidos convergem com a literatura sobre a relação entre federalismo fiscal e finanças locais e sugerem que o sistema vigente de distribuição de rendas governamentais do petróleo gera ineficiências. No entanto, a evidência também é um alerta para as propostas que visam ampliar o escopo de beneficiários. Desta maneira, esperamos ter contribuído para a discussão acerca da redistribuição das rendas do petróleo entre os entes federados, bem como para o debate sobre a adequação do atual marco regulatório do petróleo.

\section{REFERÊNCIAS}

AIGNER, D. J.; LOVELL, C. A. K.; SCHMIDT, P. Formulation and Estimation of Stochastic Frontier Production Function Models. In: Rand Paper, Santa Monica, California, 1976, 28 p. The Rand Paper Series. Disponível em: <http://www.qascores.org/pubs/papers/2008/P5649.pdf>. Acesso em: 01.agosto.2009.

ARAGON, F.; GAYOSO, V. Intergovernmental transfers and fiscal effort in Peruvian local governments. 2005. Munich Personal RePEc Archive. Disponível em: <http://mpra. ub.uni-muenchen.de/2108/>. Acesso em: 04. jan. 2010. 
BATTESE, G. Frontier production functions and technical efficiency: a survey of empirical applications in agricultural economics. Agricultural Economics. v.7. p.185-208, 1992.

BATTESE, G. E.; COELLI, T. J. A Model for Technical Inefficiency Effects in a Stochastic Frontier Production Function for Panel Data. Empirical Economics, Vienna, v. 20, n. 2, p. 325-332, jun. 1995.

BREGMAN, D. Um Estudo sobre a Aplicação dos Royalties Petrolíferos no Brasil. Brasília: ESAF, p.78, 2007.

PRÊMIO BNDES DE DISSERTAÇÕES DE MESTRADO, XX, 1998, Disparidades interregionais, Capacidade de Obtenção de Recursos Tributários. Esforço Fiscal e Gasto Público no Federalismo Brasileiro., Rio de Janeiro: BNDES,1998.

NOVA, L.C. Análise do impacto social de receitas provenientes de royalties do petróleo em municípios do estado da Bahia. Dissertação de Mestrado - Universidade de Brasília, 2005.

FERNANDES, C. F. A Evolução da Arrecadação de Royalties do Petróleo no Brasil e seu Impacto sobre o Desenvolvimento Econômico do Estado do Rio de Janeiro. Rio de Janeiro, p.72, 2007.

GIVISIEZ, G. H. N.; OLIVEIRA, E. L. Royalties do Petróleo e Educação: análise da eficiência da alocação. Petróleo Royalties \& Região, Campos dos Goytacazes, v. 6, n. 22, p. 4-6, 2008.

SEMINÁRIO SOBRE A ECONOMIA MINEIRA, 9 ,2000. Existe Trade-off entre Receitas Próprias e Transferências? O Caso dos Municípios Mineiros. In: Diamantina. Anais Eletrônicos. Belo Horizonte: CEDEPLAR, 2000. Disponível em: < http://www.cedeplar.ufmg.br/diamantina2000/2000/pontual.pdf>. Acesso em: 27 nov. 2009.

POSTALI, F. A. S. Petroleum royalties and regional development in Brazil: The economic growth of recipient towns. Resources Policy, v.34, p.205-213, 2009.

POSTALI, F. A. S.; NISHIJIMA, M. Encontro Nacional de Economia, XXXVI, Salvador, 2008. O retorno social dos royalties do petróleo nos municípios brasileiros: anais.Salvador: ANPEC, 2008.

POSTALI, F. A. S; ROCHA, F. Encontro Nacional de Economia, XXXVII, Foz do Iguaçu, 2009. Resource windfalls, fiscal effort and public spending: evidence from Brazilian municipalities: anais. Foz do Iguaçu: ANPEC, 2009.

QUEIROZ, C.R.A.; Postali, F.A.S. Rendas do petróleo e eficiência tributária dos municípios brasileiros. Working paper, 2010.

REIS, E. J.; Blanco. F. A. Capacidade tributária dos estados brasileiros 1970/90. Economia Brasileira em Perspectiva. v. 1. p. 325-353. Rio de Janeiro: IPEA, 1996.

RIBEIRO, E. P; SHIKIDA, C. D. Encontro de Economia Mineira, IX, 2000. Existe trade-off entre receitas próprias e transferências? $\mathrm{O}$ caso dos municípios mineiros: anais. Diamantina: CEDEPLAR/UFMG, 2000.

SERRA, R. V. Contribuições para o Debate Acerca da Repartição dos Royalties Petrolíferos no Brasil. Campinas, p.289, 2005.

SHAH, A. The Reform of Intergovernmental fiscal relations in developing and emerging market economies. Policy and Research Series. The World Bank, n.23, 1994. 
